\section{Genetic Diversity of South African Bottle Gourd [Lagenaria siceraria (Molina) Standl.] Landraces Revealed by Simple Sequence Repeat Markers}

\author{
Jacob Mashilo ${ }^{1}$
}

Crop Science Discipline, University of KwaZulu-Natal, Private Bag X01, Scottsville 3209, Pietermaritzburg, South Africa; and Limpopo Department of Agriculture - Towoomba Research Station, Private Bag X1615, Bela-Bela 0480, Limpopo, South Africa

\section{Hussein Shimelis}

African Centre for Crop Improvement (ACCI), University of KwaZulu-Natal, Private Bag X01, Scottsville 3209, Pietermaritzburg, KwaZulu-Natal, South Africa

\author{
Alfred Odindo \\ Crop Science Discipline, University of KwaZulu-Natal, Private Bag X01, \\ Scottsville 3209, Pietermaritzburg, KwaZulu-Natal, South Africa
}

\section{Beyene Amelework}

African Centre for Crop Improvement (ACCI), University of KwaZulu-Natal, Private Bag X01, Scottsville 3209, Pietermaritzburg, KwaZulu-Natal, South Africa

Additional index words. bottle gourd, genetic diversity, landrace, simple sequence repeat markers

\begin{abstract}
Bottle gourd [Lagenaria siceraria (Molina) Standl.] landraces are widely grown in South Africa, and genetic diversity analysis is necessary to identify promising genotypes for breeding or systematic conservation. Sixty-seven diverse bottle gourd landraces were genotyped using 14 selected simple sequence repeat (SSR) markers. The number of alleles detected per marker ranged from 4 to 11, with a total of 86 putative alleles being amplified. Allele sizes ranged from 145 to 330 base pair (bp). Number of effective alleles $\left(N_{e}\right)$ ranged from 1.58 to 6.14 with a mean of 3.10. Allelic richness varied from 3.00 to 8.90 with a mean of 5.23. Expected heterozygosity $\left(H_{e}\right)$ values ranged from 0.37 to 0.84 with a mean of 0.65 . The mean polymorphic information content (PIC) was 0.57. Jaccard's coefficient of similarity values ranged from 0.00 to 1.00 , with a mean of 0.63. Analysis of molecular variance (AMOVA) revealed that $79 \%, 17 \%$, and $4 \%$ of the variation in bottle gourd landraces was attributable to among landraces, within landraces, and between populations, respectively. The study established the existence of considerable genetic diversity among South African bottle gourd landraces. Unique landraces such as BG-4, BG-6, BG-8, BG-9, and BG-15 from cluster I; BG-55, BG-42, BG-57, and BG-58 from cluster II; BG-28, BG-23, BG-29, and BG-34 from cluster III were selected based on their highest dissimilarity index. These could be useful for bottle gourd breeding and systematic conservation.
\end{abstract}

Bottle gourd [Lagenaria siceraria (Molina) Standl.] belongs to the Cucurbitaceae family. It is a diploid $(2 n=2 x=22)$ vine crop widely grown in rural communities in South Africa (Achigan-Dako et al., 2008; Beevy and Kuriachan, 1996). The genus Lagenaria consists of five wild species:

Received for publication 6 Nov. 2015. Accepted for publication 9 Jan. 2016.

The University of KwaZulu-Natal and the National Research Foundation of South Africa are acknowledged for financial support of this study.

${ }^{1}$ Corresponding author. E-mail: jacobmashilo@ yahoo.com. oil. Some bottle gourd types are exclusively grown for their seeds (Achigan-Dako et al., 2008). Bottle gourd also serves as a rootstock in watermelon breeding to control soilborne diseases and to manage low soil temperature stress (Lee, 1994; Yetişir and Sari, 2003).

Bottle gourd exhibits significant genetic variation with respect to fruit size and shape (Gurcan et al., 2015; Morimoto et al., 2005; $\mathrm{Xu}$ et al., 2014; Yetişir et al., 2008), fruit shell thickness, fruit length and fruit width (Harika et al., 2012; Koffi et al., 2009; Morimoto et al., 2005), and seed morpho types (Decker-Walters et al., 2004; Morimoto et al., 2005; Schlumbaum and Vandorpe, 2012; Yetişir et al., 2008). This variation is attributed to farmers' longterm selection of the crop, which is often driven by specific sociocultural preferences and use, cultural practices, and the environment (Mladenovic et al., 2012). Genetic advancement during selection depends on the availability of genotypes possessing favorable alleles for desired traits, which relies on the available genetic diversity (Smith et al., 1991).

Phenotypic markers have been used to characterize and evaluate bottle gourd genetic resources, which employed various descriptor lists of morphoagronomic traits (Koffi et al., 2009; Morimoto et al., 2005; Yetişir et al., 2008). Molecular marker-based characterization is a powerful and complementary tool to phenotyping. Molecular markers are independent of environmental effects and provide more robust data on genetic distance estimates (Decker-Walters et al., 2004; Lefebvre et al., 2001; Pagnotta et al., 2009).

Various molecular markers have been used to assess genetic variability in bottle gourd, namely, randomly amplified polymorphic DNA, amplified fragment length polymorphism, SSR or microsatellite markers, inter-SSR single nucleotide polymorphism, and allozyme markers (Decker-Walters et al., 2001; Koffi et al., 2009; Saxena et al., 2015; $\mathrm{Xu}$ et al., 2014). SSRs are the marker of choice for genetic diversity analysis studies because of their high degree of polymorphism and random distribution across the genome (Gong et al., 2012; Ji et al., 2012; Varshney et al., 2005). SSR markers have been successfully used to determine the level of genetic diversity in bottle gourd (Bhawna et al., 2015a; Gonzalo et al., 2005; Saxena et al., 2015; Watcharawongpaiboon and Chunwongse, 2008). Sarao et al. (2013) fingerprinted 20 accessions of bottle gourd in India using 20 SSR primers and reported the discriminatory power of these markers. $\mathrm{Xu}$ et al. (2011) also used SSR markers to determine the genetic diversity of bottle gourd genotypes from China.

Bottle gourd is an under-researched genetic resource in South Africa (van Rensburg et al., 2007; van Wyk, 2011). In the country, small-holder farmers grow unimproved landraces, which exhibit great morphological diversity with respect to fruit and seed morphology. Despite the possible genetic 
variability and potential use of bottle gourd in South Africa, there is no recent and detailed information regarding its systematic characterization using molecular markers. Genetic diversity analysis using molecular markers may effectively characterize the South African bottle gourd landraces for systematic selection for breeding or for strategic conservation. Therefore, the objective of this study was to assess the genetic diversity present among 67 bottle gourd landraces in South Africa using selected polymorphic SSR markers.

\section{Materials and Methods}

Plant materials. Sixty-seven bottle gourd landraces collected from Capricorn $\left(23^{\circ} 36^{\prime} 44.38^{\prime \prime} \mathrm{S} ; 29^{\circ} 13^{\prime} 55.48^{\prime \prime} \mathrm{E}\right)$ and Vhembe $\left(22^{\circ} 03^{\prime} 53^{\prime \prime} \mathrm{S} ; 28^{\circ} 50^{\prime} 00.03^{\prime \prime} \mathrm{E}\right)$ districts of the Limpopo Province of South Africa were information related to the collection sites of landraces.

DNA extraction, purification, and quantification. Seed of diverse bottle gourd landraces were planted in seedling trays at the Controlled Environment Facility, University of KwaZulu-Natal, Pietermaritzburg $\left(29^{\circ} 37^{\prime} 51.75^{\prime \prime}\right.$ S; 30²3'59.10" E), South Africa. Young fresh leaves were harvested from 20 plants per landrace 4 weeks after planting. The leaf samples were sent to INCOTEC PROTEIOS Laboratory (Incotech used for the study. Table 1 summarizes

South Africa Pty Ltd, Mkondeni, Pietermaritzburg, South Africa) for SSR analysis. The DNA was extracted following the CTAB (mixed alkyltrimethylammonium bromide) protocol (DNA extraction buffer) as described by CIMMYT (2005). The concentration of the extracted DNA was determined using $0.7 \%$ Tris-borate-ethylenediaminetetraacetic acid agarose gel. A working concentration of $10 \mathrm{ng} \cdot \mu \mathrm{L}^{-1}$ was standardized for all extracted DNA (Erasmus, 2008). The samples were bulked and used in SSR amplification.

Polymerase chain reaction (PCR) and $S S R$ analyses. All samples were used in bulked amplification, using DNA extracted from the leaf material. SSR sequences were amplified through PCR using SSR primers specific for bottle gourd. Fourteen SSR markers were used for the analysis (Table 2). The markers were selected based on their high PIC and that they were developed being specific for bottle gourd (Xu et al., 2011). High PIC values suggest that markers may have high discriminatory power to distinguish differences between the genotypes. PCR were performed using $12 \mu \mathrm{L}$ of reaction mixture containing $1 \mathrm{X}$ PCR buffer, $2.5 \mathrm{~mm} \mathrm{Mg}^{++}, 0.2 \mu \mathrm{L}$ each of dinucleotide triphosphates (Bioline), $1 \mathrm{U}$ of Taq polymerase (Bioline), and 5-10 ng of genomic DNA. Primers were labeled with a 104 fluorescent dye. Two primers were provided for the amplification of each SSR locus: one

Table 1. List of 67 bottle gourd landraces used in the study with collection districts in Limpopo Province of South Africa.

\begin{tabular}{|c|c|c|c|c|c|}
\hline Serial No. & Entry & District & Serial No. & Entry & District \\
\hline 1 & BG-03 & Vhembe & 35 & BG-43 & Capricorn \\
\hline 2 & BG-04 & Capricorn & 36 & BG-44 & Capricorn \\
\hline 3 & BG-05 & Capricorn & 37 & BG-45 & Capricorn \\
\hline 4 & BG-06 & Vhembe & 38 & BG-46 & Capricorn \\
\hline 5 & BG-07 & Vhembe & 39 & BG-47 & Capricorn \\
\hline 6 & BG-08 & Vhembe & 40 & BG-48 & Capricorn \\
\hline 7 & BG-09 & Vhembe & 41 & BG-51 & Capricorn \\
\hline 8 & BG-10 & Vhembe & 42 & BG-52 & Capricorn \\
\hline 9 & BG-11 & Vhembe & 43 & BG-53 & Capricorn \\
\hline 10 & BG-12 & Vhembe & 44 & BG-55 & Capricorn \\
\hline 11 & BG-13 & Vhembe & 45 & BG-56 & Capricorn \\
\hline 12 & BG-15 & Vhembe & 46 & BG-57 & Capricorn \\
\hline 13 & BG-16 & Capricorn & 47 & BG-58 & Capricorn \\
\hline 14 & BG-17 & Capricorn & 48 & BG-59 & Capricorn \\
\hline 15 & BG-18 & Capricorn & 49 & BG-60 & Capricorn \\
\hline 16 & BG-19 & Capricorn & 50 & BG-61 & Capricorn \\
\hline 17 & BG-22 & Capricorn & 51 & BG-62 & Capricorn \\
\hline 18 & BG-23 & Capricorn & 52 & BG-64 & Capricorn \\
\hline 19 & BG-24 & Capricorn & 53 & BG-65 & Capricorn \\
\hline 20 & BG-25 & Vhembe & 54 & BG-66 & Capricorn \\
\hline 21 & BG-26 & Capricorn & 55 & BG-67 & Capricorn \\
\hline 22 & BG-27 & Capricorn & 56 & BG-68 & Capricorn \\
\hline 23 & BG-28 & Capricorn & 57 & BG-70 & Capricorn \\
\hline 24 & BG-29 & Capricorn & 58 & BG-71 & Capricorn \\
\hline 25 & BG-30 & Capricorn & 59 & BG-72 & Capricorn \\
\hline 26 & BG-31 & Capricorn & 60 & BG-73 & Vhembe \\
\hline 27 & BG-32 & Capricorn & 61 & BG-74 & Vhembe \\
\hline 28 & BG-33 & Capricorn & 62 & BG-75 & Vhembe \\
\hline 29 & BG-34 & Capricorn & 63 & BG-76 & Vhembe \\
\hline 30 & BG-35 & Capricorn & 64 & BG-77 & Capricorn \\
\hline 31 & BG-36 & Capricorn & 65 & BG-79 & Capricorn \\
\hline 32 & BG-40 & Capricorn & 66 & BG-80 & Capricorn \\
\hline 33 & BG-41 & Capricorn & 67 & BG-81 & Capricorn \\
\hline 34 & BG-42 & Capricorn & & & \\
\hline
\end{tabular}

tailed forward primer $(0.05 \mu \mathrm{mol})$ and one normal reverse primer $(0.25 \mu \mathrm{mol})$. The initial denaturation step was performed at $94{ }^{\circ} \mathrm{C}$ for $2 \mathrm{~min}$, followed by 33 cycles at $94{ }^{\circ} \mathrm{C}$ for $30 \mathrm{~s}$. Annealing of primer at primer specific $3{ }^{\circ} \mathrm{C}$ for $30 \mathrm{~s}$ and $72{ }^{\circ} \mathrm{C}$ for $45 \mathrm{~s}$ with a final extension for 20 minutes (Erasmus, 2008). PCR products were fluorescently labeled and separated by capillary electrophoresis on an ABI 3130 automatic sequencer (Applied Biosystems, Johannesburg, South Africa).

Data analysis. Genetic diversity parameters, such as number of alleles per locus $\left(N_{a}\right)$, number of effective alleles per locus $\left(N_{e}\right)$, allelic richness $\left(A_{r}\right)$, and expected heterozygosity $\left(H_{e}\right)$ were calculated using GenAlex version 6.5 (Peakell and Smouse, 2007). PIC was calculated using the formula: PIC $=1-\Sigma P_{i j}^{2}$, where $P_{\mathrm{ij}}$ is the frequency of $j$ th allele of the $i$ th locus (Nagy et al., 2012). The number of polymorphic loci was estimated for each predetermined group, based on the districts of collection. Allelic richness was estimated by using the rarefaction method implemented in HP-Rare 1.0 (Kalinowski, 2005). Further, an indirect estimate of the level of gene flow $\left(N_{m}\right)$ between the genotypes was calculated using the formula: $N_{m}=0.25\left(1-F_{\mathrm{ST}} / F_{\mathrm{ST}}\right)$ using GenAlex. Nei's unbiased genetic distance was also estimated using GenAlex. Genetic differentiation $\left(F_{\mathrm{ST}}\right)$ was computed according to Weir and Cockerham's Q methods using [Q]FSTAT (Weir and Cockerham, 1984). The partitioning of total genetic variation within and between the districts of collection and among the landraces was done using an AMOVA procedure using GenALEX.

Cluster analysis. Genetic relationships among the landraces were determined using neighbor-joining algorithm using the unweighted pair group method using arithmetic average (UPGMA) in DARwin 6.0 (Perrier and Jacquemoud-Collet, 2006). The dendogram was generated based on Jaccard's dissimilarity matrix using binary data $(0=$ absent and $1=$ present) to capture all the alleles amplified. Bootstrap analysis was performed for node construction using 10,000 bootstrap values to estimate the reliability of the clustering pattern.

\section{Results}

Polymorphism and allelic diversity of SSR markers. Estimates of genetic parameters are presented in Table 3. The SSR markers generated a total of 86 putative alleles (different fragment sizes) among the bottle gourd landraces. Number of alleles ranged from 4 for the markers LSR074, LSR088, LSR108, and LSR112 to 11 for LSR020, with a mean of 6.14 per locus. Number of effective alleles ranged from 1.58 to 6.14 with a mean of 3.1 . The value of $N_{e}$ for $50 \%$ of the loci was $>2$, while for $50 \%$ of the loci $N_{e}$ was $>3$. Allelic richness ranged from 3 to 8.9 with a mean of 5.23. Allele size ranged from 145 to $330 \mathrm{bp}$. The highest variation in allele size was 
Table 2. Description of the simple sequence repeat (SSR) primers used for bottle gourd genetic diversity analysis.

\begin{tabular}{|c|c|c|c|}
\hline SSR primer & Forward primer & Reverse primer & Repeat type \\
\hline LSR020 & AACTGAAACCATTAACGAAGGC & AATAAGCAGCAACCATGTCAAC & G \\
\hline LSR030 & GGAGACAAAACCAACAACGAA & GAAAATGCAGACAAAGAAAGCC & AT \\
\hline LSR047 & CAATAGAGTAGGGTGGGGCATA & TAAAATAGTGGGAGAGCAAGGG & $\mathrm{TC}$ \\
\hline LSR056 & TAATAATGCCACTGCACATGGT & AGATGAATCCCAATATCCCAGA & CTT \\
\hline LSR063 & AAGAGAGGGGCAGGAAGTAAAT & AGAAAACACACAGTACGCCTCC & ATT \\
\hline LSR088 & CCAACTATCACСССТАCAATCA & GGACAGAACCTAAAAGAAAGAAGAG & ATA \\
\hline LSR108 & AGCTCTGGGAAGAGGAAGAGTA & GCAGACAGAAGAAGAAAGTTAGAGA & AG \\
\hline LSR109 & TGGGGTAGAAATTGAAGAGGAG & TTGGATCAGCTTGGGTTTTACT & GA \\
\hline LSR112 & СТCTCTATATGTCTAATTCCTCGCC & CAAATTCACAGTTGTTGTCACG & TTCT \\
\hline
\end{tabular}

observed in markers LSR030 (155-330 bp) and LSR077 (159-320 bp), respectively. The lowest variation in allele size was observed in marker LSR108. Shannon's information index $(I)$ ranged from 0.93 to 1.99 with a mean of 1.29. Expected heterozygosity values ranged from 0.37 to 0.84 with a mean of 0.65. Marker LSR063 had the lowest and marker LSR015 had the highest expected heterozygosity values. The PIC values ranged from 0.37 for the marker LSR063 to 0.84 for marker LSR015 with a mean of 0.57 . In the present study nine SSR markers used had PIC values $>0.50$. These were classified as informative markers to establish the genetic relationship of bottle gourd landrace collections.

The level of gene flow $\left(N_{m}\right)$ between the landraces was the highest for the markers LSR040, LSR056, LSR077, and LSR109 and the lowest for the markers LSR088, LSR112, and LSR020 with a mean of 24.46. Genetic differentiation $\left(F_{\mathrm{ST}}\right)$ ranged from 0 to 0.05 with a mean of 0.04 . Marked differences were detected in the mean number of alleles and private alleles per locus between the two districts (Capricorn and Vhembe) of collection (Table 4). Capricorn district showed the highest number of private alleles (13) than Vhembe (4). Conversely, Vhembe district showed the highest number of effective alleles (3.58) than Capricorn district (2.81). Increased allelic richness was observed at Vhembe district, while a slightly lower allelic richness was detected at Capricorn district. Shannon's information index estimates were closely similar between the two districts. Expected heterozygosity, PIC, and average genetic distance were slightly higher in Vhembe than Capricorn district. Nei's unbiased genetic distance between Capricorn and Vhembe district was 0.09 .

Cluster analysis. Jaccard's coefficient of similarity values ranged from 0.07 to 1.0 , with a mean of 0.63 among the 67 landraces (data not shown). Among the test bottle gourd landraces, the following pairs were identical with the lowest dissimilarity index: BG-70 and BG-77, BG-56 and BG-76, BG51 and BG-61, BG-60 and BG-65, BG-62 and BG-81, BG-65 and BG-70, and BG-65 and BG-77. Conversely, BG-6 was distantly related to BG-28; BG-52; BG-55; BG-57,

Table 3. Genetic parameters generated by 14 SSR markers among 67 landrace collections of bottle gourd from South Africa.

\begin{tabular}{lrccccccrc}
\hline & \multicolumn{8}{c}{ Genetic parameters } \\
\cline { 2 - 8 } Loci & $N_{a}$ & $N_{e}$ & $A_{r}$ & $A_{s r}$ & $I$ & $H_{e}$ & PIC & \multicolumn{1}{c}{$N_{m}$} & $F_{\text {ST }}$ \\
LSR011 & 7 & 3.91 & 6.43 & $162-190$ & 1.62 & 0.75 & 0.71 & 7.50 & 0.03 \\
LSR015 & 10 & 6.14 & 8.86 & $146-201$ & 1.99 & 0.84 & 0.83 & 6.68 & 0.04 \\
LSR020 & 11 & 3.04 & 5.66 & $161-202$ & 1.41 & 0.68 & 0.61 & 4.76 & 0.05 \\
LSR030 & 8 & 4.14 & 6.83 & $155-330$ & 1.69 & 0.76 & 0.73 & 8.29 & 0.03 \\
LSR040 & 7 & 3.06 & 6.87 & $175-214$ & 1.46 & 0.68 & 0.60 & 18.42 & 0.01 \\
LSR047 & 6 & 2.82 & 5.55 & $145-175$ & 1.36 & 0.65 & 0.55 & 8.18 & 0.03 \\
LSR056 & 3 & 2.68 & 3.00 & $155-193$ & 1.03 & 0.63 & 0.57 & 81.45 & 0.00 \\
LSR063 & 5 & 1.58 & 3.84 & $158-204$ & 0.77 & 0.37 & 0.37 & 7.95 & 0.03 \\
LSR074 & 4 & 2.21 & 3.50 & $175-203$ & 0.97 & 0.55 & 0.41 & 7.46 & 0.03 \\
LSR077 & 6 & 3.43 & 5.90 & $159-320$ & 1.41 & 0.71 & 0.67 & 60.16 & 0.00 \\
LSR088 & 4 & 2.21 & 3.45 & $155-204$ & 0.93 & 0.55 & 0.43 & 1.83 & 0.12 \\
LSR108 & 4 & 2.21 & 3.50 & $158-177$ & 0.97 & 0.55 & 0.41 & 7.46 & 0.03 \\
LSR109 & 7 & 3.68 & 6.18 & $240-273$ & 1.48 & 0.73 & 0.70 & 116.99 & 0.00 \\
LSR112 & 4 & 2.25 & 3.58 & $157-225$ & 0.97 & 0.56 & 0.44 & 2.53 & 0.09 \\
Mean & 6.14 & 3.10 & 5.23 & - & 1.29 & 0.65 & 0.57 & 24.26 & 0.04 \\
SE & 0.64 & 0.31 & 0.45 & - & 0.09 & 0.03 & 0.04 & 9.52 & 0.01 \\
\hline
\end{tabular}

$N_{a}=$ number of alleles per locus; $N_{e}=$ number of effective alleles per locus; $A_{r}=$ allelic richness; $A_{s r}=$ allele size range (bp); $I=$ Shannon's information index; $H_{e}=$ expected heterozygosity; PIC = polymorphic information content; $N_{m}=$ gene flow; $F_{S T}=$ genetic differentiation.

Table 4. Estimation of genetic parameters among 67 landrace collections of bottle gourd using 14 simple sequence repeat markers based on districts of collection.

\begin{tabular}{lcc}
\hline & \multicolumn{2}{c}{ Districts of collection } \\
\cline { 2 - 3 } Genetic parameters & Capricorn & Vhembe \\
\hline Number of private alleles & 13 & 4 \\
Number of alleles & 5.86 & 5.21 \\
Allelic richness & 4.91 & 5.43 \\
Number of effective alleles & 2.81 & 3.58 \\
Shannon's information index & 1.21 & 1.36 \\
Heterozygosity & 0.61 & 0.71 \\
Polymorphic information content & 0.50 & 0.63 \\
Average genetic distance & 0.61 & 0.70 \\
\hline
\end{tabular}

BG-58, and BG-66. The landraces BG-4 and BG-55, BG-8 and BG-58, and BG-9 and BG-58 were also distantly related with high dissimilarity values. The landraces that were distantly related showing the highest dissimilarity index were the following: BG-15 with BG-45, BG-55, and BG-28; BG-18 with BG-28, BG-29, BG-42, and BG-55; BG-19 with BG-34, BG-42, and BG-55; and BG-25 with BG-55, BG-17, and BG-58. Other landraces that were distantly related included: BG-35 with BG-52; BG-58, BG40 with BG-52 and BG-58.

The UPGMA-derived dendogram based on the Jaccard's dissimilarity clustering pattern using the neighbor-joining method in DARwin 6.0 classified the bottle gourd landraces into three major clusters, namely, cluster I, cluster II, and cluster III (Fig. 1). Cluster I was further subdivided into two subclusters consisting of 27 landraces. Cluster II had three subclusters consisting of 35 landraces. Cluster III had two subclusters consisting of five genotypes. Based on the highest genetic dissimilarity values of landraces in different clusters, the following unique and genetically complementary landraces were selected for breeding and systematic conservation. Landraces selected from cluster I included: BG-4, BG-6, BG-8, BG-9, BG-15, BG-17, BG-18, BG-19, BG22, BG-24, BG-25, BG-35, and BG-40, whereas selections from cluster II included: BG-42, BG-52, BG-55, BG-57, BG-58, and 


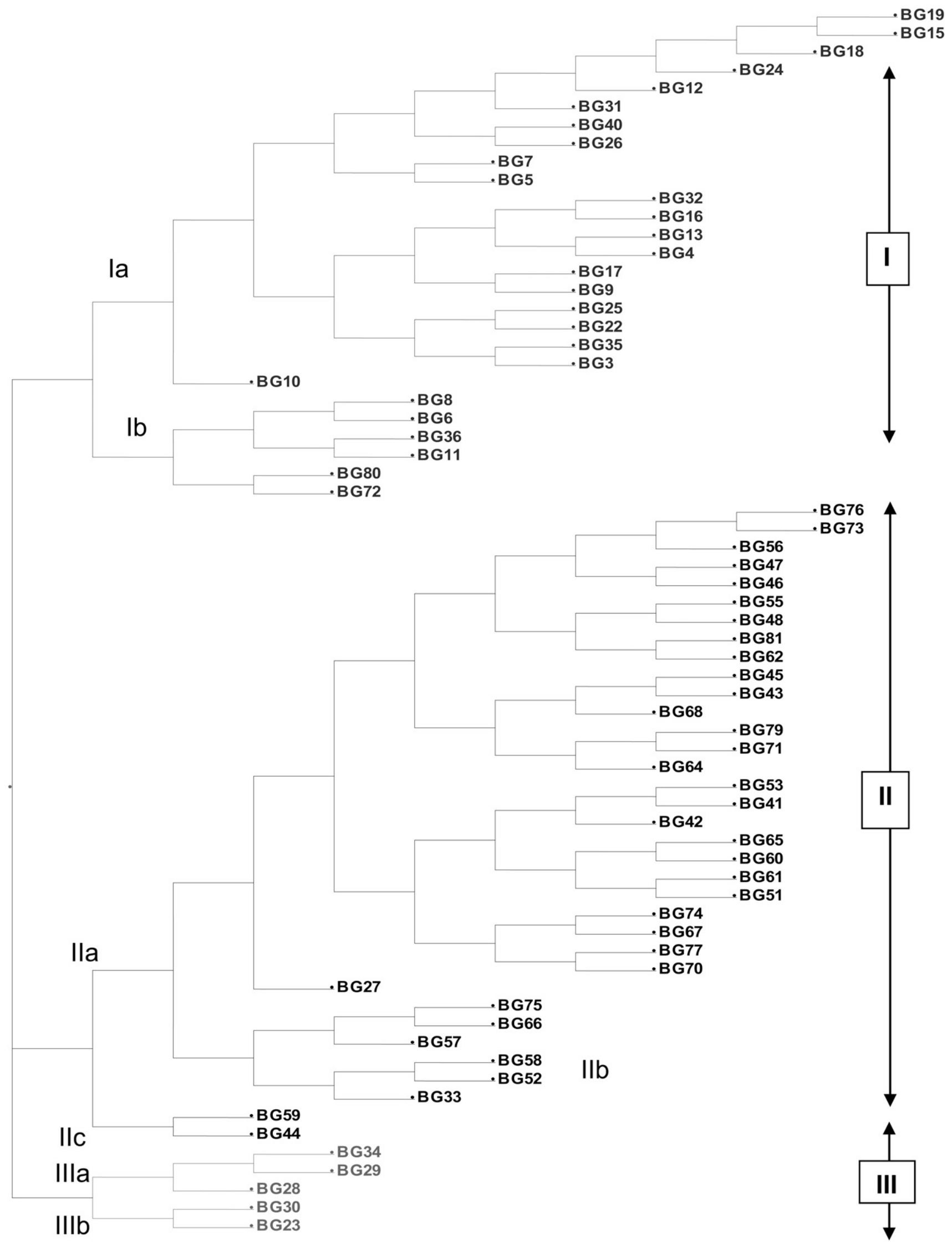

Fig. 1. Neighbor-joining dendrogram using the unweighted pair group method using arithmetic averagebased on Jaccard's dissimilarity matrix revealing genetic relationships among 67 bottle gourd landraces based on simple sequence repeat markers. Ia, Ib; IIa, IIb, and IIc; and IIIa and IIIb denote subgroups within the clusters. 
BG-66; and from cluster III included: BG23, BG-28, BG-29, and BG-34. The selected landraces have unique agronomic attributes and fruit shape (Fig. 2). These landraces would be genetically complementary for bottle gourd breeding.
Analysis of molecular variance. AMOVA revealed that $79 \%$ of variation was attributable to among landraces, while $17 \%$ and $4 \%$
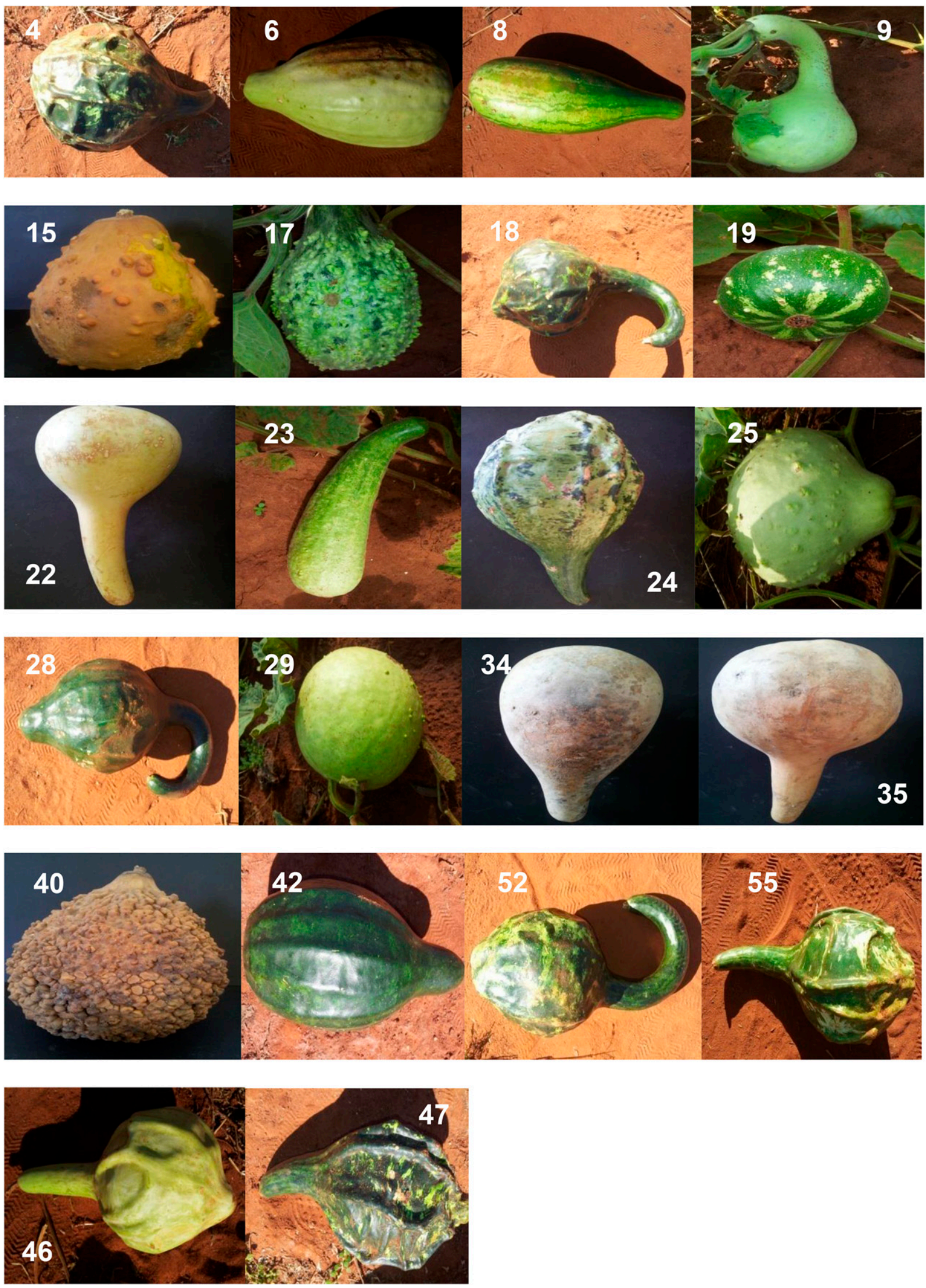

Fig. 2. Variation in fruit architecture of bottle gourd landraces selected showing the highest dissimilarity values revealed by 14 simple sequence repeat markers. Note: numbers on the photos designate entries presented in Table 1. 
Table 5. Analysis of molecular variance for the simple sequence repeat markers among and within the 67 bottle gourd landraces studied.

\begin{tabular}{lrccccc}
\hline Source of variation & df & SS & MS & $\begin{array}{c}\text { Estimated } \\
\text { variation }\end{array}$ & $\begin{array}{c}\text { Percentage } \\
\text { variation }\end{array}$ & F-Statistics \\
\hline Between populations & 1 & 12.703 & 12.703 & 0.15 & 4 & 0.057 \\
Among landraces & 65 & 437.25 & 6.727 & 2.959 & 79 & 0.001 \\
Within landraces & 67 & 34 & 0.507 & 0.637 & 17 & 0.001 \\
Total & 133 & 483.96 & 3.639 & 3.746 & 100 & \\
\hline df
\end{tabular}

$\mathrm{df}=$ degrees of freedom; $\mathrm{SS}=$ sum of squares; $\mathrm{MS}=$ mean squares.

of the total variation was allocated to within landrace and between populations, respectively (Table 5).

\section{Discussion}

The present study assessed genetic diversity of South African bottle gourd landraces using SSR markers. The number of alleles ranged from 4 to 11 with a mean of 6.14 per locus. This was higher than 2 to 4 alleles (average $=2.6$ ) reported by Sarao et al. (2013). Using 14 polymorphic SSR loci, $\mathrm{Xu}$ et al. (2014) reported 2 to 8 alleles (mean $=3.64$ ) per marker in 44 bottle gourd entries, which is less than the current findings. Koffi et al. (2009) reported the number of alleles per locus varying from 1.0 to 1.4 with a mean of 1.2 suggesting a low allelic richness. Yildiz et al. (2015) and Bhawna et al. (2015b) reported the number of alleles ranging from 1 to 5 (mean $=1.64)$ and 2 to 4 alleles (mean $=2.84)$ in bottle gourd, respectively. In the current study, the number of effective alleles ranged from 1.58 to 6.14 with a mean of 3.1. These values were higher than reported by Bhawna et al. (2015b) with 1.46-3.29 (mean $=2.08$ ). This indicates a high level of genetic diversity among South African bottle gourd landraces useful for breeding and strategic conservation.

The selected SSR markers amplified a total of 86 alleles with allele size ranges of 155 to $330 \mathrm{bp}$. A total of 26 alleles were reported by Sarao et al. (2013) and 51 alleles by $\mathrm{Xu}$ et al. (2011). The higher number of alleles generated by SSR markers in the present study suggest a wide genetic diversity that can be exploited for breeding. The high allelic number and richness in the present study implies the presence of significant genetic variation among tested landraces. This could be attributed to higher cross pollination of bottle gourd or long-term selection by farmers. Furthermore, bottle gourd is a cross-pollinated crop, where recurrent exchange of gametes occurs between different genotypes (Bhawna et al., 2014).

Expected heterozygosity values in this study ranged from 0.37 to 0.84 with a mean of 0.657 . Koffi et al. (2009) reported a low average heterozygosity of 0.053 with ranges of 0 to 1.4 in bottle gourd. The levels of observed heterozygosity in the present study are considerably higher than reported for wild species. Expected heterozygosity were reported to be 0.46 for annuals, 0.55 for shortlived perennials, 0.41 for self-fertilizing, 0.60 for mixed breeding, and close to 0.65 for outcrossing species of bottle gourd (Nybom,
2004). The high levels of expected heterozygosity indicate a presence of significant level of genetic diversity, which will enhance selection efficiency.

In the current study, the PIC values ranged from 0.39 to 0.84 (mean $=0.57$ ). These values are comparatively higher than those reported by Sarao et al. (2013) with 0.23 to 0.73 and $\mathrm{Xu}$ et al. (2011) with 0.11 to 0.72 $($ mean $=0.4)$. Yildiz et al. $(2015)$ reported PIC values of 0.12 to $0.52($ mean $=0.15)$ in bottle gourd, whereas Bhawna et al. (2015b) found PIC values of 0.05 to 0.54 (average = 0.33 ) using 19 SSR markers. The PIC defines a relative measure of the informativeness of a marker or discriminatory power of a polymorphic marker, which depends on the number of alleles and relative frequency of an allele in the population (Bhawna et al., 2015b; Gaikward et al., 2008). In the present study, the highest PIC value was detected using marker LSR015 (0.84), closely followed by LSR020 (0.83). Also, a large proportion of the markers used exhibited a greater discriminatory power. Generally most of the markers had PIC values $>0.6$, suggesting a high discriminating ability of the SSR markers for classifying the bottle gourd landraces.

A low genetic differentiation $\left(F_{S T}\right)$ of 0.04 was found in the present study. According to Wright (1978), $F_{S T}$ values ranging from 0 to 0.005 indicates low, $0.05-0.15$ moderate, $0.15-0.25$ high, and above 0.25 very high genetic differentiations. The low $F_{S T}$ values in the present study could be the result of the high level of gene flow among bottle gourd landraces. The gene flow $\left(N_{m}\right)$ in this study was 24.26 higher than 7.27 reported by Bhawna et al. (2015b). The high gene flow and low genetic differentiation between landraces in the current study may suggest a high rate of gene exchange between bottle gourd landraces due to its outcrossing. Also, high gene flow could be attributed to a high degree of movement of germplasm probably through frequent seed exchange among farmers. Farmers recycle seed harvested from previous season or source from neighboring farmers or local markets for planting (Koffi et al., 2009). This practice results in genetic variability among individuals within populations.

The dendogram based on SSR genotyping classified the bottle gourd landraces into three main clusters revealing great genetic variation. Further, landraces were not grouped based on district of collection suggesting sharing common morphological traits. This suggests that bottle gourd use and selection must have been driven by farmers' specific sociocultural preferences and use. For example, fruits with handles are used to make containers called "sego" for drinking water and traditional beer (M. Kobe, personal communication), whereas large-oval fruits are used to make containers for storing water and food (K.R. Mahlong, personal communication). This indicates that germplasm collection programs should be based on morphological variation rather than geographical background (Yildiz et al., 2015). Results of this study are in agreement with the findings of Bhawna et al. (2015b), Sarao et al. (2013), Xu et al. (2011), and Yetişir et al. (2008) who reported that clustering of bottle gourd genotypes was independent of geographical location. Decker-Walters et al. (2001) characterized 74 genotypes of bottle gourd from a global sample collections. The authors revealed that the lines from diverse origins (Africa, Asia, and the New World) did not group based on their geographic background. Yildiz et al. (2015) reported that population structure analysis classified bottle gourd in two subpopulations defined by fruit shape, rather than geographical origin.

The present study estimated the Shannon's information index $(I)$ with a mean value of 1.33. This was higher than 0.80 reported by Bhawna et al. (2015b). Genetic distance estimates ranged from 0 to 1.0 , with a mean of 0.63 suggesting wide genetic diversity among the bottle gourd landraces. Sarao et al. (2013) and $\mathrm{Xu}$ et al. (2011) reported high genetic similarity coefficients of 0.96 and 0.94 in bottle gourd, in that order. Bhawna et al. (2015b) reported Jaccard's coefficient of similarity values ranging from 0.11 to 0.75 , with a mean of 0.41 among 42 bottle gourd genotypes. These values were lower than the current study suggesting differences in bottle gourd genetic diversity.

\section{Conclusion}

The SSR analysis revealed the existence of wide genetic diversity among South African bottle gourd landraces. Unique landraces such as BG-4, BG-6, BG-8, BG-9, and BG-15 from cluster I; BG-55, BG-42, BG-57, and BG-58 from cluster II; BG-28, BG-23, BG29 , and BG-34 from cluster III were selected based on their highest dissimilarity index. These could be useful for bottle gourd breeding and systematic conservation.

\section{Literature Cited}

Achigan-Dako, E.G., J. Fuchs, A. Ahanchede, and F.R. Blattner. 2008. Flow cytometric analysis in Lagenaria siceraria (Cucurbitaceae) indicates correlation of genome size with usage types and growing elevation. Plant Syst. Evol. 276:9-19.

Beevy, S.S. and P. Kuriachan. 1996. Chromosome numbers of South Indian cucurbitaceae and a note on the cytological evolution in the family. J. Cytol. Gen. 31:65-71.

Bhawna, A.M.Z., L. Arya, C. Ram, A.K. Sureja, and M. Verma. 2015a. Development of novel gene-based microsatellite markers for robust genotyping purposes in Lagenaria siceraria. Sci. Hort. 191:15-24. 
Bhawna, A.M.Z., L. Arya, D. Saha, A.K. Sureja, C. Pandey, and M. Verma. 2014. Population structure and genetic diversity in bottle gourd [Lagenaria siceraria (Mol.) Standl.] germplasm from India assessed by ISSR markers. Plant Syst. Evol. 300:767-773.

Bhawna, A.M.Z., L. Arya, and M. Verma. 2015b. Transferability of cucumber microsatellite markers used for phylogenetic analysis and population structure study in bottle gourd (Lagenaria siceraria (Mol.) Standl.). Appl. Biochem. Biotechnol. 175:2206-2223.

CIMMYT. 2005. Laboratory protocols: CIMMYT applied molecular genetics laboratory. 3rd ed. CIMMYT, Mexico.

Decker-Walters, D.S., J. Staub, A. López-Sesé, and E. Nakata. 2001. Diversity in landraces and cultivars of bottle gourd (Lagenaria siceraria; Cucurbitaceae) as assessed by random amplified polymorphic DNA. Genet. Resources Crop Evol. 48:369-380.

Decker-Walters, D.S., M. Wilkins-Ellert, S.M. Chung, and J.E. Staub. 2004. Discovery and genetic assessment of wild bottle gourd [Lagenaria siceraria (Mol.) Standley; Cucurbitaceae] from Zimbabwe. Econ. Bot. 58:501-508.

Erasmus, T.E. 2008. Genetic diversity of proprietary inbred lines of sunflower, determined by mapped SSR markers and total protein analysis. School of Agricultural Sciences and Agribusiness, University of KwaZulu-Natal, Pietermaritzburg, $\mathrm{PhD}$ thesis.

Gaikward, A.B., A.K. Singh, D. Chandel, J.L. Karihaloo, and J.E. Staub. 2008. Amplified fragment length polymorphism analysis provides strategies of bitter gourd (Momordica charantia L.). HortScience 43:127-133.

Ghule, B.V., M.H. Ghanti, P.G. Yeole, and A.N. Saoji. 2007. Diuretic activity of Lagenaria siceraria fruit extracts in rats. Indian J. Pharm. Sci. 69:817-819.

Gong, L., H.S. Paris, M.H. Nee, G. Stift, M. Pachner, J. Vollmann, and T. Lelley. 2012. Genetic relationships and evolution in Cucurbita pepo (pumpkin, squash, gourd) as revealed by simple sequence repeat polymorphisms. Theor. Appl. Genet. 124:875-891.

Gonzalo, M.J., M. Oliver, J. Garcia-Mas, A. Monfort, R. Dolcet-Sanjuan, N. Katzir, P. Arús, and A.J. Monforte. 2005. Simple-sequence repeat markers used in merging linkage maps of melon (Cucumis melo L.). Theor. Appl. Genet. 110:802-811.

Gurcan, K., A. Say, and H. Yesitir. 2015. A study of genetic diversity in bottle gourd [Lagenaria siceraria (Molina) Standl.] population, and implication for the historical origins on bottle gourds in Turkey. Genet. Resources Crop Evol. 62:321-333.

Harika, M., V.D. Gasti, T. Shantappa, R. Mulge, A.M. Shirol, A.B. Mastiholdi, and M.S. Kulkarni. 2012. Evaluation of bottle gourd genotypes [Lagenaria siceraria (Mol.) Standl.] for various horticultural characters. Karnataka J. Agr. Sci. 25:241-244.

Jeffrey, C. 1976. Cucurbitaceae, p. 1-157. In: E. Milne-Redhead and R.M. Polhill (eds.). Flora of tropical East Africa. Crown agents for oversea governments and administrations, London, UK.
Ji, Y., Y. Luo, B. Hou, W. Wang, J. Zhao, L. Yang, Q. Xue, and X. Ding. 2012. Development of polymorphic microsatellite loci in Momordica charantia (Cucurbitaceae) and their transferability to other cucurbit species. Sci. Hort. 140:115-118.

Kalinowski, S.T. 2005. HP-RARE1.0: A computer program for performing rarefaction on measures of allelic richness. Mol. Ecol. Notes 5:187-189.

Koffi, K.K., G.K. Anzera, M. Malice, Y. Dje, P. Bertin, J.P. Baudoin, and I.A. Zoro Bi. 2009. Morphological and allozyme variation in a collection of Lagenaria siceraria (Molina) Standl. from Cote D'Ivoire. Biotechnol. Agron. Soc. Environ. 13:257-270.

Lee, J.M. 1994. Cultivation of grafted vegetables I. Current status, grafting methods and benefits. HortScience 29:235-239.

Lefebvre, V., B. Goffinet, J.C. Chauvet, B. Caromel, P. Signoret, R. Brand, and A. Palloix. 2001. Evaluation of genetic distances between pepper inbred lines for cultivar protection purposes: Comparison of AFLP, RAPD and phenotypic data. Theor. Appl. Genet. 102:741750.

Mladenovic, E., J. Berenji, J.B.V. Ognjanov, M. Ljubojevic, and J. Cukanovic. 2012. Genetic variability of bottle gourd (Lagenaria siceraria (Mol.) Standley and its morphological characterization by multivariate analysis. Arch. Biol. Sci. (Belgrade) 64:573-583.

Morimoto, Y., P. Maundu, H. Fujimaki, and H. Morishima. 2005. Diversity of landraces of the white-flowered gourd (Lagenaria siceraria) and its wild relatives in Kenya: Fruit and seed morphology. Genet. Resources Crop Evol. 52:737-747.

Nagy, S., P. Poczai, I. Cernák, A.M. Gorji, G. Hegedüs, and J. Taller. 2012. PIC calc: An online program to calculate polymorphic information content for molecular genetic studies. Biochem. Genet. 50:670-672.

Nybom, H. 2004. Comparison of different nuclear DNA markers for estimating intraspecific genetic diversity in plants. Mol. Ecol. 13:11431155.

Pagnotta, M.A., L. Mondini, P. Codianni, and C. Fares. 2009. Agronomical, quality, and molecular characterization of twenty Italian emmer wheat (Triticum dicoccon) accessions. Genet. Resources Crop Evol. 56:299-310.

Peakell, R. and P.E. Smouse. 2007. GENALEX 6: Genetic analysis in Excel. Population software for teaching and research. Mol. Ecol. Notes 6:288-295.

Perrier, X. and J.P. Jacquemoud-Collet. 2006. DARwin software. Dissimilarity Analysis and Representation for Windows. 15 Feb. 2015. $<$ http://www.darwin.cirad.fr/darwinhtml $>$.

Sarao, N.K., M.P. Neha, and K. Kaur. 2013. Microsatellite-based DNA fingerprinting and genetic diversity of bottle gourd genotypes. Plant Genet. Resour. Charact. Util. (First View Article):1-4.

Saxena, S., A. Singh, S. Archak, T. Behera, J. John, S. Meshram, and A. Gaikwad. 2015. Development of novel simple sequence repeat markers in bitter gourd (Momordica charantia L.) through enriched genomic libraries and their utilization in analysis of genetic diversity and cross-species transferability. Appl. Biochem. Biotechnol. 175:93-118.

Schlumbaum, A. and P. Vandorpe. 2012. A short history of Lagenaria siceraria (bottle gourd) in the Roman provinces: Morphotypes and archaeogenetics. Veg. Hist. Archaeobot. 21:499-509.

Smith, S.E., A.A. Doss, and M. Warburton. 1991. Morphological and agronomic variation in North African and Arabian alfalfas. Crop Sci. 31:1159-1163.

van Rensburg, W.S.J., W. van Averbeke, R. Slabbert, M. Faber, P. van Jaarsveld, I. van Heerden, F. Wenhold, and A. Oelofse. 2007. African leafy vegetables in South Africa. Water SA 33:317-326.

van Wyk, B.E. 2011. The potential of South African plants in the development of new food and beverage products. S. Afr. J. Bot. 77:857868.

Varshney, R.K., A. Graner, and M.E. Sorrells. 2005. Genic microsatellite markers in plants: Features and applications. Trends Biotechnol. 23:48-55.

Watcharawongpaiboon, N. and J. Chunwongse. 2008. Development and characterization of microsatellite markers from an enriched genomic library of Cucumber (Cucumis sativus). Plant Breed. 127:74-81.

Weir, B.S. and C.C. Cockerham. 1984. Estimating $F$-statistics for the analysis of population structure. Evolution 38:1358-1370.

Whitaker, T.W. 1971. Endemism and precolumbian migration of the bottle gourd, Lagenaria siceraria (Mol.) Standl, p. 320-337. In: C.L. Riley, J.C. Kelley, C.W. Pennington, and R.L. Runds (eds.). Man across the sea. University of Texas Press, Austin, TX.

Wright, S. 1978. Evolution and the genetics of populations: Variability within and among natural populations. University of Chicago Press, Chicago, IL.

Xu, P., X. Wu, J. Luo, B. Wang, Y. Liu, J.D. Ehlers, Z. Lu, and G. Li. 2011. Partial sequencing of the bottle gourd genome reveals markers useful for phylogenetic analysis and breeding. BMC Genomics 12:467.

Xu, P., S. Xu, X. Wu, T. Tao, B. Wang, S. Wang, D. Qin, Z. Lu, and G. Li. 2014. Population genomic analyses from low-coverage RADSeq data: A case study on the non-model cucurbit bottle gourd. Plant J. 77:430-442.

Yetişir, H. and N. Sari. 2003. Effect of different rootstock on plant growth, yield and quality of watermelon. Austral. J. Exp. Agr. 43:12691274.

Yetişir, H., M. Şakar, and S. Serçe. 2008. Collection and morphological characterization of Lagenaria siceraria germplasm from the Mediterranean region of Turkey. Genet. Resources Crop Evol. 55:1257-1266.

Yildiz, M., H.E. Cuevas, S. Sensoy, C. Erdinc, and F.S. Baloch. 2015. Transferability of cucurbita SSR markers for genetic diversity assessment of Turkish bottle gourd (Lagenaria siceraria) genetic resources. Biochem. Syst. Ecol. 59: $45-53$. 